\title{
Commentary: Is the era of bilateral internal thoracic artery coming for diabetic patients? Yes, 取决于你问谁 [depends who you ask]
}

\author{
Chaim Locker, MD
}

\author{
From the Department of Cardiovascular Surgery, Mayo Clinic, Rochester, Minn \\ Disclosures: Author has nothing to disclose with regard to commercial support. \\ Received for publication Feb 28, 2019; accepted for publication Feb 28, 2019; available ahead of print April 20, \\ 2019. \\ Address for reprints: Chaim Locker, MD, Department of Cardiovascular Surgery, Mayo Clinic, 200 First St SW, \\ Rochester, MN 55905 (E-mail: lekerlocker.chaim@mayo.edu). \\ J Thorac Cardiovasc Surg 2019;158:1573-5 \\ $0022-5223 / \$ 36.00$ \\ Copyright (C) 2019 by The American Association for Thoracic Surgery \\ https://doi.org/10.1016/j.jtcvs.2019.02.124
}

Approximately $50 \%$ of patients undergoing coronary artery bypass grafting (CABG) have diabetes. ${ }^{1}$ Survival after $\mathrm{CABG}$ in patients with diabetes is worse $^{2}$ because of the severity of coronary disease, extent of associated atherosclerotic vascular disease, and peripheral organ complications of diabetes. On the other hand, it has been shown that patients with diabetes may have the most to gain from bilateral internal thoracic artery (BITA) grafting, because they usually have a more severe, diffuse, and distal coronary disease, and BITA grafts possess well-documented unique histologic and physiologic properties ${ }^{3}$ superior to the radial artery (RA) and saphenous vein grafts (SVGs), which can ameliorate the diabetic-induced coronary endothelial dysfunction and accelerated atherosclerotic disease process. There have been numerous recent investigations seeking to define the preferred treatment in this sharply increasing subgroup of patients. The perceived higher risk of deep sternal wound infection (DSWI) related to BITA grafting and morbidity and the financial penalties of the complication have precluded the use of the best conduits (internal thoracic artery [ITA]) for diabetic patients.

In this issue of the Journal, Zhuo and colleagues ${ }^{4}$ present a large and comprehensive meta-analysis including 1 randomized controlled trial and 17 observational studies of 129,871 diabetic patients who underwent isolated CABG. Of those, 124,233 patients were operated on with the use of single internal thoracic artery (SITA) grafting and 5638 with the use of BITA grafting; 1128 received a BITA graft harvest with the skeletonized technique. The important findings of this investigation are that the skeletonized ITA harvest technique completely mitigated the difference between the SITA and BITA groups in terms of risk of DSWI rates ( $2.46 \%$ vs $2.48 \%$, respectively), and in-hospital mortality rate was similar in both groups. BITA grafting significantly improved long-term overall survival

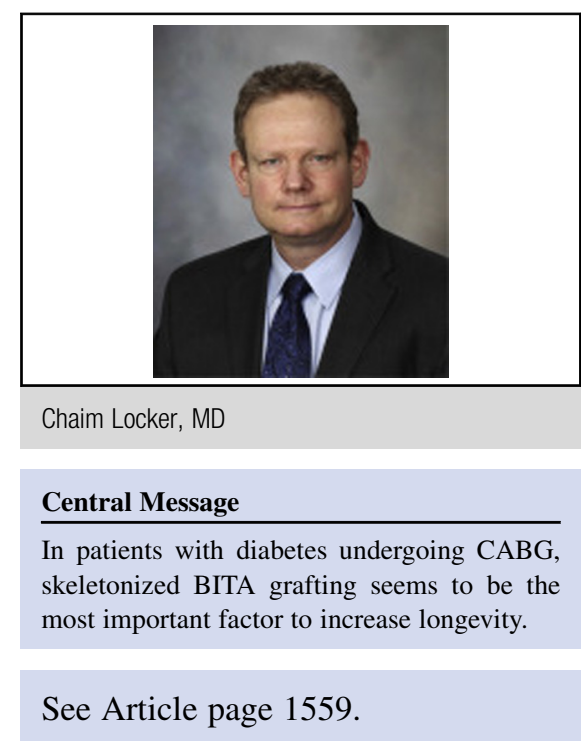

(hazard ratio [HR], 1.41, $P<.001$ ) and long-term cardiac mortality-free survival compared with SITA (HR, 3.15; $P<.001)$.

The strength of this report is the overall large cohort of diabetic patients, the use of propensity matching, and the subset analysis of patients undergoing the skeletonized ITA harvest technique. The authors also stratified the studies by insulin- versus non-insulin-treated patients and assessed the quality of the included observational studies by the appropriate scales and guidelines. Analysis of the 3 most important clinical implications of SITA versus BITA in diabetic patients showed the DSWI rate in skeletonized versus pedicled ITA harvest techniques, early and longterm survival differences, and cardiac-related mortality, and those provide an important adjunct to the current literature.

There are some obvious weaknesses to this study. First, most of the included studies were of a retrospective nature, many without matched cohorts. Second, we do not have data on preoperative blood glucose level control as reflected by the level of glycated hemoglobin (HbA1C). It is now recognized that $\mathrm{HbA1C}$ has a major impact on the longterm results of CABG in diabetic patients, ${ }^{5}$ and this was included in only 2 studies of this meta-analysis. The authors should be commended for emphasizing the lack of these important data in previous studies. 
The use of the skeletonized ITA harvest technique is mandatory when using BITA grafts in general, but especially in diabetic patients, to preserve an adequate blood supply to the sternum and prevent DSWI. ${ }^{6}$ Many studies reported results on diabetic patients without stratifying or analyzing outcomes of the cohorts by the ITA harvest technique. ${ }^{7}$ Benedetto and colleagues, ${ }^{8}$ in their report of outcomes from the ART trial, have clearly shown that by using a skeletonized ITA harvesting technique, the risk of sternal wound infection with BITA grafting was similar to the risk of sternal wound infection after standard pedicled SITA harvesting, even in patients at higher risk, such as insulin-dependent diabetic patients, women, and those with increased body mass index. This correlates well with the findings of the current meta-analysis and with numerous previous studies. ${ }^{9,10}$ Unfortunately, the skeletonized ITA harvest technique is not universally accepted because of the learning curve and anticipated additional time required. A recent editorial has described the current barriers to multiarterial grafting, the proposed solutions, and the responsible parties in an outstanding informative table, ${ }^{11}$ and the authors also referred to their recent report showing similar perioperative and long-term outcomes of RA and right ITA grafting in patients with diabetes, ${ }^{12}$ but emphasized their preference to first use BITA grafting in diabetic patients. Raja and colleagues ${ }^{13}$ showed that BITA did not increase the operative risk, including DSWI rate, improved long-term outcomes, and improved overall survival, when compared with SITA/RA. This advantage appeared to be greater among diabetic and obese patients. Notably, Goldstone and colleagues,${ }^{14}$ in their recent large report of 59,000 patients undergoing isolated CABG in California, did not stratify the diabetic cohort as a distinct subgroup or report the BITA harvest technique of skeletonized versus pedicled; thus, their conclusion of overall increased risk of sternal wound infection associated with the right ITA should be interpreted cautiously.

Gaudino and colleagues, ${ }^{15}$ in their patient-level report comparing the RA with SVG in CABG surgery, did not present any significant benefit by the use of the RA compared with SVG $(P=.35)$ in the subgroup and interaction term analysis in the diabetic subgroup of patients included in the RADIAL project for the primary composite outcome of death, myocardial infarction, and repeat revascularization. In a study analyzing the outcome of patients undergoing CABG with the use of 1,2 , or 3 arterial grafts (of those, the RA [96\%] and right ITA [4\%] were the additional arterial grafts to the left ITA), Schwann and colleagues ${ }^{16}$ found that among the 4377 diabetic patients included, the survival advantage of using 2 arteries versus 1 artery was nonsignificant, whereas it was significant for 3 arteries versus 1 artery (HR, 0.74).

A benchmark study in the Journal ${ }^{17}$ analyzing the outcomes of approximately 12,000 consecutive diabetic patients undergoing CABG concluded that the most important impact on 20-year survival was achieved by the use of BITA grafting. In another important report, Raza and colleagues ${ }^{18}$ showed that graft patency was not inferior in diabetic patients over 20 years follow-up and the patency rate of BITA remained greater than $90 \%$, outperforming the SVG patency rate of $40 \%$, and those rates were similar both in diabetic persons and in nondiabetic persons. ${ }^{18}$ Although the cohorts were not stratified by the type of diabetes and late coronary angiography was mostly symptom driven, these findings strongly support the use of skeletonized BITA in diabetic patients. Thus, on the basis of additional recent large national ${ }^{19}$ and international reports, ${ }^{20}$ which show a clear survival advantage with BITA grafting in diabetic patients, it seems that the era of skeletonized BITA is coming for diabetic patients.

Moreover, one could argue that it may be unjustified to financially penalize for DSWI in CABG with BITA performed on patients with diabetes, when our goal is to provide the best conduit available to extend their survival. This approach could have been waived by defining skeletonized BITA grafting as a quality metric in CABG in general, and especially in diabetic patients, that should have been incentivized by payers, especially when substantial data exist that survival is not jeopardized even in the rare occasion of DSWI. The benefit of skeletonized BITA grafting seems to clearly outweigh the risk of DSWI in nondiabetic and diabetic patients.

We at the Mayo Clinic recently analyzed our data with a cohort of approximately 4000 consecutive diabetic patients requiring myocardial revascularization for multivessel coronary artery disease over 20 years of follow-up. The impact of multiarterial grafting on long-term survival was impressive compared with all other myocardial revascularization methods provided in diabetic patients, ${ }^{21}$ but when we further stratified the multiarterial grafting group into the BITA versus the SITA/RA subgroups, we found a significant long-term outcome difference between the 2 groups, with BITA grafting being significantly superior (soon to be published). Thus, in our practice, in diabetic patients with a reasonable life expectancy, skeletonized BITA grafting is used in preference to SITA/RA or SITA/SVG strategies unless a combination of increased clinical risk factors for DSWI clearly exist, for example, patient of female gender, morbidly obese, insulin-treated diabetes, uncontrolled preoperative blood glucose levels as reflected by an $\mathrm{HbA} 1 \mathrm{C}$ level greater than $7 \%$, and severe clinically apparent chronic obstructive pulmonary disease. We previously showed that extending BITA grafting to higher-risk patients in our practice, including to diabetic patients, benefited those subgroups with a significant long-term survival advantage. ${ }^{22}$ Notably, at our clinic, the ITA is routinely harvested almost exclusively by using the skeletonized harvest technique. ${ }^{23}$ 
Our goal in every CABG operation and especially in diabetic patients should be the appropriate selection and harvest of conduits based on patient risk factors, clinical characteristics, predicted longevity, and the completeness of revascularization. Protocol-driven perioperative management and strict blood glucose level control are critically important. Future investigations are required to better define the ways we are treating the diabetic population. For this, the following are recommended: (1) standardization of our reports to include the most relevant and important risk factors (eg, HbA1C, insulin vs oral treatment, type 1 vs 2 diabetes); (2) stratification by the surgical ITA harvest techniques of skeletonized versus pedicled (mainly in retrospective analyses); (3) evidence-based requirement for the standard use of skeletonized ITA harvest technique in future designed prospective randomized trials; (4) accurate report of the non-left anterior descending coronary targets grafted including the severity of coronary stenoses; and (5) standardization of definition of DSWI.

The conduction of well-designed and carefully tailored randomized controlled trials (eg, the ART trial, ${ }^{24}$ notwithstanding the puzzling outcome difference between the "intention to treat" and "as treated" cohorts) and the adoption of advanced medical treatments, ${ }^{25}$ as well as newer surgical techniques, may be prudent to benefit this important and fast growing subgroup of patients.

\section{References}

1. D'Agostino RS, Jacobs JP, Bahwar V, Fernandez FG, Paone G, Wormuth DW, et al. The Society of Thoracic Surgeons adult cardiac surgery database: 2018 update on outcomes and quality. Ann Thorac Surg. 2018;105:15-23.

2. Raza S, Sabik JF III, Ainkaran P, Blackstone EH. Coronary artery bypass grafting in diabetics: a growing health care cost crisis. J Thorac Cardiovasc Surg. 2015; 150:304-12.

3. Gaudino M, Toesca A, Maggiano N, Pragliola C, Possati G. Localization of nitric oxide synthase type III in the internal thoracic and radial arteries and the great saphenous vein: a comparative immunohistochemical study. J Thorac Cardiovasc Surg. 2003; 125:1510-5

4. Zhuo P, Zhu P, Nie Z, Zheng S. Is the era of bilateral internal thoracic artery grafting coming for diabetic patients? An updated meta-analysis. J Thorac Cardiovasc Surg. 2019;158:1559-70.e2.

5. Robich MP, Iribarne A, Leavitt BJ, Malenka DJ, Quinn RD, Olmstaed EM, et al. Intensity of glycemic control affects long-term survival after coronary artery bypass graft surgery. Ann Thorac Surg. 2019;107:477-85.

6. Cohen AJ, Lockman J, Loberboym M, Bder O, Cohen N, Medalion B, et al. Assessment of sternal vascularity with single photon emission computed tomography after harvesting of the internal thoracic artery. J Thorac Cardiovasc Surg. 1999;118:496-502.

7. Takagi H, Goto S, Watanabe T, Mizuno Y, Kawai N, Umemoto T. A metaanalysis of adjusted hazard ratios from 20 observational studies of bilateral versus single internal thoracic coronary artery bypass grafting. J Thorac Cardiovasc Surg. 2014;148:1282-90.

8. Benedetto U, Altman DG, Gerry S, Gray A, Lees B, Pawlaczyk R, et al. Pedicled and skeletonized single and bilateral internal thoracic artery grafts and the incidence of sternal wound complications: insights from the arterial revascularization trial. J Thorac Cardiovasc Surg. 2016;152:270-6.

9. Dai C, Lu Z, Zhu H, Xue S, Lian F. Bilateral internal mammary artery grafting and risk of sternal wound infection: evidence from observational studies. Ann Thorac Surg. 2013;65:1938-45.

10. Deo SV, Shah IK, Dunaly SM, Erwin PJ, Locker C, Altarabsheh SE, et al. Bilateral internal thoracic artery harvest and deep sternal wound infection in diabetic patients. Ann Thorac Surg. 2013;95:862-9.

11. Bakaeen FG, Svensson LG. Why don't we kill 2 birds with 1 stone? Less adverse cardiac events and improved survival with multiarterial coronary artery bypass grafting. Circulation. 2018;137:1708-11.

12. Raza S, Blackstone EH, Houghtaling PL, Koprivanac M, Ravichandren K Javadikasgari $\mathrm{H}$, et al. Similar outcomes in diabetes patients after coronary artery bypass grafting with single internal thoracic artery plus radial artery grafting and bilateral internal thoracic artery grafting. Ann Thorac Surg. 2017;104:1923-32.

13. Raja SG, Benedetto U, Jothidasan A, Jujjavarapu RK, Ukwu UF, De Robertis F, et al. Right internal mammary artery versus radial artery as second arterial conduit in coronary artery bypass grafting: a case-control study of 1526 patients. Int J Surg. 2015;16:183-9.

14. Goldstone AB, Chiu P, Baiocchi M, Wang H, Lingala B, Boyd JH, et al. Second arterial versus venous conduits for multivessel coronary artery bypass surgery in California. Circulation. 2018;137:1698-707.

15. Gaudino M, Benedetto U, Fremes S, Biondi-Zoccai G, Sedrakyan A, Puskas JD, et al. Radial-artery or saphenous vein grafts in coronary artery bypass surgery. $N$ Engl J Med. 2018;378:2069-77.

16. Schwann TA, Karim A, Sleiman E, Yammine MB, Taranbaugh RF, Engoren M, et al. Incremental value of increasing number of arterial grafts: the effect of diabetes mellitus. Ann Thorac Surg. 2018;105:1737-44.

17. Raza S, Sabik JF, Masabni K, Ainkaran P, Lytle BW, Blackstone EH. Surgica revascularization techniques that minimize surgical risk and maximize late survival after coronary artery bypass grafting in patients with diabetes mellitus. $J$ Thorac Cardiovasc Surg. 2014;148:1257-66.

18. Raza S, Blackstone EH, Houghtaling PL, Rajeswaran J, Riaz H, Bakaeen FG et al. Influence of diabetes on long-term coronary artery bypass graft patency. J Am Coll Cardiol. 2017;70:515-24.

19. Irbirane A, Westbrook BM, Malenka DJ, Schmoker JD, McCullough JN Leavitt BJ, et al. Should diabetes be a contraindication to bilateral internal mammary artery grafting? Ann Thorac Surg. 2018;105:709-14.

20. Ohira S, Miyata H, Yamazki S, Numata S, Motomura N, Takamoto S, et al. Deep sternal wound infection after bilateral internal thoracic artery grafting: insights from a Japanese national database. J Thorac Cardiovasc Surg. 2019;157:166-73.

21. Locker C, Schaff HV, Lahr B, Frye RL, Daly RC, Said SM, et al. In diabetic patients multiple arterial grafts improve long-term survival compared with surgery or stents. J Am Coll Cardiol. 2018;71:A27.

22. Saran N, Locker C, Said SM, Daly RC, Maltais S, Stulak JM, et al. Current trends in bilateral internal thoracic artery use for coronary revascularization: extending benefit to high-risk patients. J Thorac Cardiovasc Surg. 2018;155:2331-43.

23. Locker $\mathrm{C}$. To skeletonize the internal thoracic artery or not to skeletonize? To be or not to be! J Thorac Cardiovasc Surg. 2018;155:229-31.

24. Taggart DP, Benedetto U, Gerry S, Altman DG, Gray AM, Lees B, et al. Bilatera versus single internal-thoracic-artery grafts at 10 years. N Engl J Med. 2019;380: 437-46.

25. O'Brien MJ, Karam SL, Wallia A, Kang RH, Cooper AJ, Lancki N, et al. Association of second-line antidiabetic medications with cardiovascular events among insured adults with type 2 diabetes. JAMA Netw Open. 2018;1:e186125. 